\title{
RELATIONSHIP BETWEEN POWER CONDITION, AGILITY, AND SPEED PERFORMANCE AMONG YOUNG ROLLER HOCKEY ELITE PLAYERS
}

original paper

( ) University School of Physical Education in Wroclaw

DOI: https://doi.org/10.5114/hm.2019.79040

\author{
ANDRE FERREIRA ${ }^{1}$, CARLA ENES ${ }^{1}$, CESAR LEAO ${ }^{1}$, LILLIAN GONCALVES ${ }^{1}$, \\ FILIPE MANUEL CLEMENTE ${ }^{1,2}$, RICARDO LIMA ${ }^{1}$, PEDRO BEZERRA $^{1,3}$, MIGUEL CAMOES $^{1}$ \\ ${ }^{1}$ Polytechnic Institute of Viana do Castelo, School of Sport and Leisure, Melgaço, Portugal \\ ${ }^{2}$ Instituto de Telecomunicações, Covilhã, Portugal \\ ${ }^{3}$ Research Center in Sports Sciences, Health Sciences and Human Development (CIDESD), Vila Real, Portugal
}

\begin{abstract}
Purpose. The study was intended to describe the correlations between speed performance $(11 \mathrm{~m}, 22 \mathrm{~m}$, and $33 \mathrm{~m})$ and agility test in skates with determinants of muscular power (squat jump, countermovement jump) in young Portuguese roller hockey athletes involved in a regional selection.

Methods. A cross-sectional study was conducted among 10 male roller hockey players with mean ( \pm SD) age of 14.20 (0.57) years, involved in the Portuguese national competition of under-15, making part of the final Oporto district selection of players to participate in inter-regional selections competition. Their mean ( \pm SD) weight, height, body mass index, and sum of the skinfolds were $58.62(8.78) \mathrm{kg}, 165.72(8.45) \mathrm{cm}, 21.26(1.52) \mathrm{kg} / \mathrm{m}^{2}, 51.80(14.91) \mathrm{mm}$, respectively. Furthermore, it strength was measured with squat jump and countermovement jump; sprinting time at $11 \mathrm{~m}, 22 \mathrm{~m}$, and 33 m was determined, as well as time in an agility $t$-test, conducted in roller skating. Spearman correlation coefficients were calculated to test the associations.

Results. Significant inverse correlations between vertical jumps, a practical method of power training monitoring, and linear velocity in skating (countermovement jump vs. speed, -0.78) were found. Despite the increasing complexity of the agility test, a moderate inverse correlation with strength was observed, too $(-0.48)$.

Conclusions. Lower limbs explosive strength turned out a strong predictor of skating linear speed and agility among young roller hockey players, providing a simple evaluation tool of important determinants of performance.
\end{abstract}

Key words: youth training athletes, strength and conditioning, sports performance

\section{Introduction}

The multidimensionality of sports performance and the variability of the skills needed to be an elite athlete purport that the number of variables able to fit an explanatory model of future performance is large [1]. Thus, the identification of predictors of success is an essential process for the selection and recruitment of promising young athletes to compete at the highest level [2]. A multidisciplinary approach is recommended for the identification of young talents, including physiological, psychological, sociological, anthropometric, physical fitness and technical factors [3].
Presumably, it seems evident that young people who have superior technical ability prevail and are assigned to become elite athletes [4], and, usually, when they are above average for their age regarding the positive determinants at the anthropometric level, they tend to be advanced at biological maturity, leading to an obvious interest into the pattern of sports performance. Still in the multifactorial model mentioned above, the relevant measures include stamina, speed, muscular strength, power, flexibility, agility, body composition, and somatotype [3].

In a sport such as roller hockey, which is characterized physiologically by its intermittent nature, alter-

Correspondence address: André Ferreira, Complexo Desportivo e Lazer, Monte de Prado 4960-320, Melgaço,

Viana do Castelo, Portugal, e-mail: andre.r.ferreira19@gmail.com

Received: April 29, 2018

Accepted for publication: May 23, 2018

Citation: Ferreira A, Enes C, Leao C, Goncalves L, Clemente FM, Lima R, Bezerra P, Camoes M. Relationship between power condition, agility, and speed performance among young roller hockey elite players. Hum Mov. 2019;20(1):24-30; doi: https:// doi.org/10.5114/hm.2019.79040. 
nating the effort intensities between the aerobic and anaerobic regimes [5] with a predominance of short actions of maximum intensity makes it clear that power and speed are physical qualities of extreme relevance for the physical performance of the players, similarly to ice hockey [6]. It is important to mention that when we speak of young athletes, we refer to growing individuals at different stages of physiological development, which are closely associated with faster or slower improvements in the above described abilities [2].

Speed can be defined by the ability to move the body in the desired direction as quickly as possible [7]. It depends on muscle strength and neuromuscular coordination; however, the intensity with which these factors manifest in speed is not yet consensual [8].

The characteristic of speed [9] is highly relevant for the hockey player, namely because of the constant challenge of achieving positional advantages [10]. With pronounced accelerations and decelerations, athletes are required to have very high levels of muscular power to modify the inertia of their body mass, so when talking about speed in roller hockey, its strong association with muscular power should not be neglected [9].

In addition, power is defined by the product of the force produced by the velocity in a given movement [11]. In this mode of intermittent regimen, characterized by a glycolytic metabolism, the type of muscle fibres predominant in athletes is IIb [12], hence the training of this ability assumes a great importance in the monitoring of the athletes' sports training, with special emphasis among youth athletes, where all movement patterns will be built.

Agility does not currently have a common definition in the literature, and the notion has undergone a lot of definition changes throughout time [13]. One of the most common determines this as a rapid movement of the whole body, with change of speed or direction in response to a stimulus [14]. This lack of definition is bound with the fact that agility is associated with more than one variable. Consequently, Young et al. [15] divides it into two components: the changes of direction, and the decision-making related to decision factors, with a further division into subcomponents [16].

There is a lack of scientific research about roller hockey, namely focusing on determinants of sports performance that allow, in a practical way, to monitor the training, enhance the work of the coach, and, consequently, improve the athletic performance of the young athletes. Thus, the present study intended to verify the correlation between speed performance in skates $(11 \mathrm{~m}, 22 \mathrm{~m}$, and $33 \mathrm{~m})$ and determinants of muscu- lar power (squat jump [SJ], countermovement jump $[\mathrm{CMJ}]$ ) in young Portuguese hockey athletes.

\section{Material and methods}

\section{Participants}

A cross-sectional study was conducted among 10 male roller hockey players with mean $( \pm S D)$ age of 14.20 (0.57) years, involved in the Portuguese national competition of under-15/-17 (U15 and U17), making part of the final Oporto district selection of players to participate in inter-regional selections competition in Portugal, March 2018. The study participants were evaluated in training conditions by trained sports science coaches.

At the time of the evaluations, the athletes were in the maintenance phase of the U15 and U17 national championship. These groups of athletes have an average of 6 hours per week of deliberate practice at the clubs that they represent. Table 1 describes the demographic and anthropometric characteristics.

Table 1. Demographic and anthropometric descriptive statistics of the study participants

\begin{tabular}{lc}
\hline Characteristics & $\begin{array}{c}\text { Subjects }(n=10), \\
\text { mean }(S D)\end{array}$ \\
\hline Age (years) & $14.20(0.57)$ \\
Weight $(\mathrm{kg})$ & $58.62(8.78)$ \\
Height $(\mathrm{cm})$ & $165.72(8.45)$ \\
BMI $\left(\mathrm{kg} / \mathrm{m}^{2}\right)$ & $21.26(1.52)$ \\
$\Sigma$ 6SKF $(\mathrm{mm})$ & $51.80(14.91)$ \\
\hline
\end{tabular}

BMI - body mass index, $\Sigma 6$ SKF - sum of 6 skinfolds

\section{Anthropometrics}

The tests were conducted in an appropriate room before the participants' first training. All subjects wore light clothing and stood barefoot. Their height was measured to the nearest $0.1 \mathrm{~cm}$ with a portable stadiometer (Seca 217, Hamburg, Germany). Weight was assessed to the nearest $0.1 \mathrm{~kg}$ with a Tanita BC-601 instrument. All procedures followed the guidelines of the International Society for the Advancement of Kinanthopometry [17].

\section{Body composition}

Eight skinfolds (triceps, subscapular, biceps, suprailiac, abdominal, supraspinal, thigh, and calf) were assessed twice (at $0.1 \mathrm{~mm}$ ) with a Harpenden caliper 
(British Indicators, Ltd., London, UK). The procedure was performed by a certified tester, following the International Society for the Advancement of Kinanthropometry recommendations [17].

The mean value of the two measurements was considered and the sum of 6 (triceps, subscapular, abdominal, supraspinal, thigh, and calf) skinfolds ( $\Sigma 6 \mathrm{SKF})$ calculated.

\section{Vertical jumps}

All jumps were performed by each participant at the same time of the day, with sports shoes. The subjects implemented a standardized warm-up period of 5 minutes. Then they performed 3 repetitions of SJ. For that, they flexed the knees to $90^{\circ}$, held the position with the arms by their waist, and after a signal, without any countermovement, performed the jump.

After all subjects had performed the SJ, they proceed to do 3 repetitions of CMJ. In this jump, they began in the upright position with the arms on the waist all throughout the jump. Upon hearing a signal, they flexed the knees and jumped as high as possible in a single movement, with legs totally straight, observing plantar flexion. In both types of jump, the subjects were required to land in the same departure point and rebound with straight legs when landing in order to avoid knee bending and alteration of measurements.

For the CMJ and SJ tests, each subject was given a minimum of $60 \mathrm{~s}$ for rest in-between jumps [18]. All the trials were performed by athletes positioned on a contact platform (Chronojump) attached to hardware (Chronopic 3, Chronojump Boscosystem, Spain). The hardware was connected to a computer which displayed the vertical jump values $(\mathrm{cm})$ from a free software (Chronojump Boscosystem Software, Spain). The best of the 3 trials was recorded to the nearest $0.1 \mathrm{~cm}$.

\section{Speed}

The speed test was conducted in an indoor gym of collective sports with specific conditions for hockey practice, adjusted to the regulations described by Fédération Internationale Roller Sports (FIRS) [19]. Four lights with sensors were placed in a straight line at the 11-m, 22-m, and 33-m mark (Figure 1), dividing the field $(44 \mathrm{~m})$ into 3 parts.

The lights and the software used for the test were products from the FitLight Sports Corp. Ontario, Canada. A commercially available product FitLight Trainer comes as a wireless system unit comprising eight

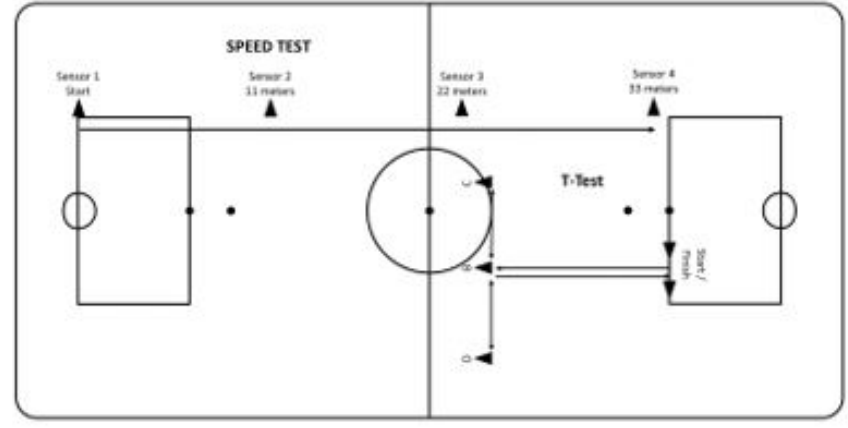

Figure 1. Schematic representation of the speed test and the T-test

LED powered lights controlled by a tablet. The lights have an inbuilt sensor which reacts to proximity or touch and deactivates the light. The system may be programmed for specific sequences of light activation and responds to the deactivation of the lights, while the timing is recorded by the controller (Figure 1).

After a standard warm-up, the players were placed behind the first mark. Then, one by one, at the controller signal, they started a sprint to the last mark at full speed. The results were then recorded. Each player did only one repetition.

\section{Agility}

The agility test was conducted in a standard roller hockey gym. The evaluation was performed through the T-test, validated by Pauole et al. [20], with an alteration because all the athletes performed the test with roller skating. The T-shaped test measures the strength and agility of the lower limbs, an important factor to meet the constant changes of direction. The test consists in covering a T-shaped path, in the shortest time possible by the athlete, with the registration of time at the control points through the photoelectric cells $[16,20]$. As shown in Figure 1, the athletes began the test in the start line, speeded up to B $(9.14 \mathrm{~m})$, then went to $C(4.57 \mathrm{~m})$, turned around to $\mathrm{D}(9.14 \mathrm{~m})$, from there directed back to $\mathrm{B}(4.57 \mathrm{~m})$ and then to the finish line $(9.14 \mathrm{~m})$. In addition, the athletes enrolled in the test were to answer external stimuli as pass and reception.

\section{Statistical analysis}

A descriptive analysis, mean and standard deviation, was performed regarding the anthropometric and fitness characteristics. Spearman's correlation coefficients were calculated to describe the relationship between power, based on vertical jumps (CMJ), agility (T-test), and speed (11 m, $22 \mathrm{~m}$, and $33 \mathrm{~m})$. 
All statistical analysis was computed with the Statistical Package for Social Sciences (SPSS, version 23.0; IBM Corporation, New York, USA).

\section{Ethical approval}

The research related to human use has been complied with all the relevant national regulations and institutional policies, has followed the tenets of the Declaration of Helsinki, and has been approved by the authors' institutional review board or an equivalent committee.

\section{Informed consent}

Informed consent has been obtained from the legal guardians of all individuals included in this study.

\section{Results}

Table 2 presents the average results obtained in the power (SJ and CMJ), speed $(11 \mathrm{~m}, 22 \mathrm{~m}$, and 33 $\mathrm{m})$ and agility (T-test) physical conditions among the young athletes. In both tests of vertical jumps, the mean
Table 2. Strength, power, speed, and agility descriptive statistics

\begin{tabular}{lcc}
\hline Physical condition & Test & Mean (SD) \\
\hline \multirow{2}{*}{ Power } & SJ $(\mathrm{cm})$ & $27.44(4.64)$ \\
& CMJ $(\mathrm{cm})$ & $30.47(4.44)$ \\
\hline \multirow{2}{*}{ Speed } & $11-\mathrm{m}(\mathrm{s})$ & $2.22(0.17)$ \\
& 22-m (s) & $3.36(0.18)$ \\
\hline Agility & 33-m (s) & $4.44(0.20)$ \\
\hline
\end{tabular}

SJ - squat jump, CMJ - countermovement jump,

11-m - 11-m linear speed, 22-m - 22-m linear speed, 33-m - 33-m linear speed

range of variation was between 27.44 and $30.47 \mathrm{~cm}$, for the SJ and CMJ, respectively. Agility was measured in roller skates and the mean time of the T-shaped test of $7.36 \mathrm{~s}$ was observed.

Figure 2 shows the linear relationship between $\mathrm{CMJ}$, as a field shoes method of power estimation, and the speed test performed on roller skating. Strong inverse linear associations were observed between $\mathrm{CMJ}$ and
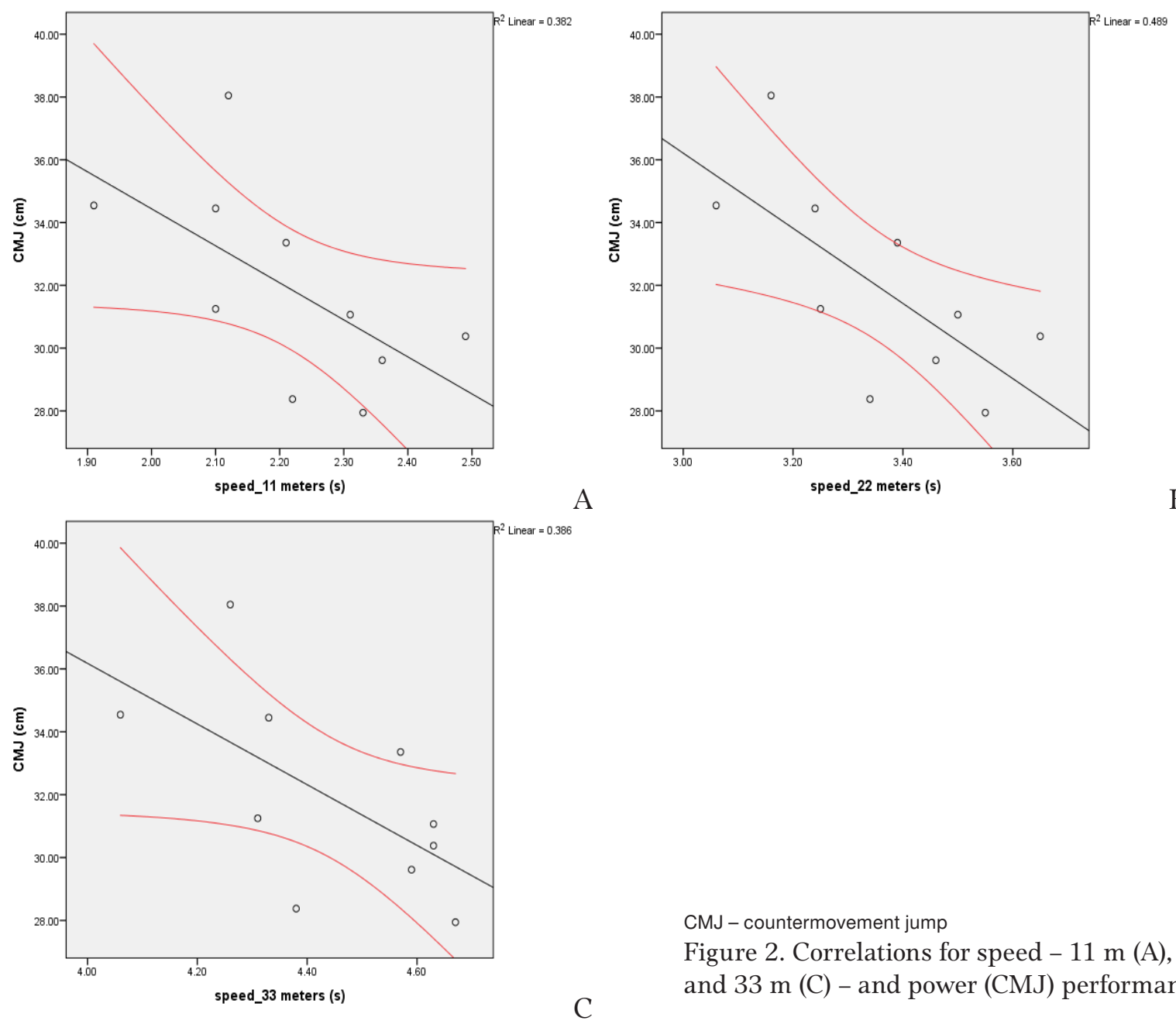

B

CMJ - countermovement jump

Figure 2. Correlations for speed - $11 \mathrm{~m}$ (A), $22 \mathrm{~m}$ (B), and $33 \mathrm{~m}(\mathrm{C})$ - and power $(\mathrm{CMJ})$ performance 
A. Ferreira et al., Power condition, agility, and speed in young athletes

Table 3. Spearman correlation coefficients among anthropometric and physical fitness conditions

\begin{tabular}{lcccc}
\hline Spearman's rho & Power & Speed & Agility & $\Sigma 6$ SKF \\
\hline Power & 1 & -0.62 & -0.48 & -0.75 \\
Speed & -0.62 & 1 & 0.41 & -0.09 \\
Agility & -0.48 & 0.041 & 1 & 0.41 \\
$\Sigma$ 6SKF & -0.75 & -0.09 & 0.41 & 1 \\
\hline
\end{tabular}

$\Sigma 6$ SKF - sum of 6 skinfolds

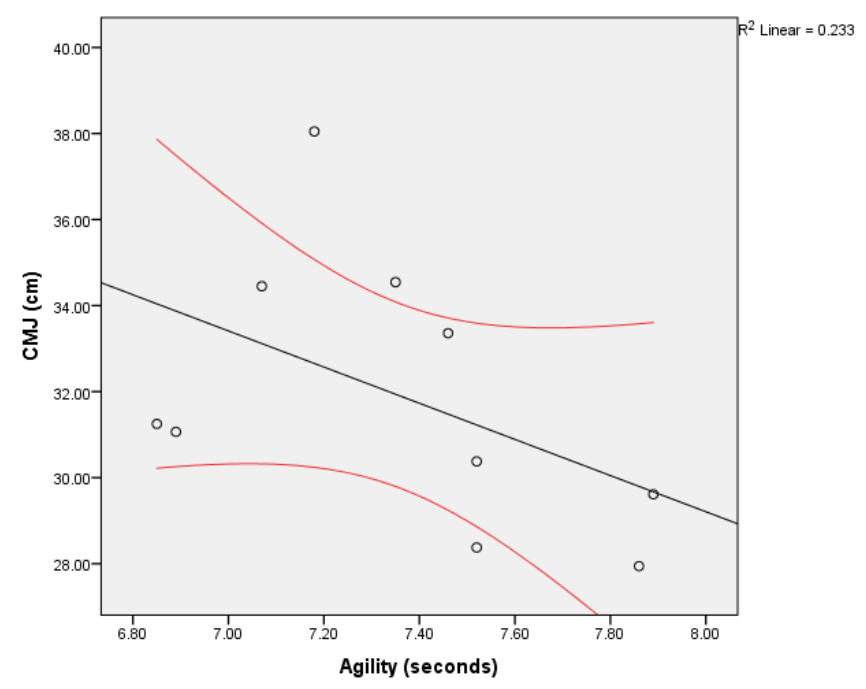

$\mathrm{CMJ}$ - countermovement jump

Figure 3. Correlations for agility and power (CMJ) performance

linear speed, in different dimensions of the field (11 m, $22 \mathrm{~m}$, and $33 \mathrm{~m}$ ), demonstrating a clear pattern of linear association. The higher the jumps, the less time in $11 \mathrm{~m}$, $22 \mathrm{~m}$, and $33 \mathrm{~m}$ of the performance test, with Spearman correlations of $-0.75,-0.77$, and -0.78 (data not shown).

In addition to the pattern illustrated above, strong correlations were maintained among the non-specific roller hockey test as $\mathrm{CMJ}$ and multidirectional test, with technical performance in the skating T-shaped circuit: -0.48 (Table 3).

In addition, Figure 3 illustrates a moderate inverse linear relationship between $\mathrm{CMJ}$ and agility. It should be noted that both tests stimulate the same energy pathway, but the agility test was performed in roller skates.

\section{Discussion}

As a simple field method of evaluating power, vertical jumps proved to be a strong predictor of linear speed in skating among young elite athletes, with a range of significant inverse correlations: SJ vs. speed $(-0.55)$; CMJ vs. speed (-0.78), and squats vs. speed
$(-0.54)$. In the association between vertical jumps and speed, acceleration in sprint seems to have great influence on CMJ performance [21-25].

In a cross-sectional study with 167 Portuguese soccer players assessed, CMJ was compared to the linear speed in $10 \mathrm{~m}$ (V10), $20 \mathrm{~m}$ (V20), and $30 \mathrm{~m}$ (V30). The data showed moderate correlations in the comparisons mentioned above: $r=0.29,0.39$, and 0.44 , respectively. In another soccer study, where 17 elite players were evaluated, higher correlations were found among vertical jump and V10 $(r=0.72)$ and V30 $(r=0.60)$. This same study also reported that half-squatting increased sprint and jumping performance in soccer players [26]. Thus, several studies have shown that vertical jumping tests are an important motor skill assessment tool among different sports. Despite roller hockey game does not require the motor ability of jumping in the different moments of the game, jumping tests consistently showed to be associated with the ability to skate faster [10, 21-24].

The jump test is not specific for roller hockey; however, it assumes a strong correlation of dependence with speed tests on skates, where the stimulated capacity is the same. Roller skating speed can be influenced by other factors that possibly bias the correlations with power, namely the technical approach of skating. However, one of the advantages in our study is that the impact of skating proficiency on speed is minimized owing to the homogeneity of the quality of the athletes, making all of them part of selection among the best regional roller hockey players in Portugal, with high ability in the technical skating approach.

As mentioned above, despite the low specificity of both jump tests with this sport, they were associated with linear velocity performed by skates. Our data allow the classification of the athletes according to a simple physical condition determinant of performance - power.

Power depends on strength and speed, therefore optimal levels of maximum strength are required for its development. Regarding the maximum strength, this can be understood as the highest value that the neuromuscular system is able to produce [11]. In a sport where all actions are performed through short and maximum intensity shifts, power training becomes crucial and must be increased in order to empower young athletes.

In addition to the linear speed, the test of agility that was carried out seems to be more representative of the global actions of the young players in this sport. This physical condition is defined as a rapid movement of the whole body, with change of speed or direction in response to a stimulus [14]. This has two im- 
portant components that are associated with the game: the changes of direction, and the decision making that is related to the decision factors $[14,16]$. Furthermore, it requires a reaction to external stimuli (reception/ pass), approaching significantly the performance to be monitored in training/play. To help develop agility, physical qualities such as strength, speed, flexibility, and coordination are required [27].

Understanding the role of agility in similar sports, such as futsal, with the same number of players and with sports shoes, this physical condition is one of the most important factors described, namely because of the comprehensive relation with changes of direction [28], very similar to the conditions required among the roller hockey players. The same was observed in ice hockey, sport in which the agility determinant seems to be more important than the maximum speed [29].

Also in football literature it is clear in pointing out that the ability of players to produce high-speed actions has a great impact on collective performance, actions that can be categorized into those requiring acceleration, maximum speed, or agility [30]. By extrapolating to roller hockey, where the playing field is reduced and the means of locomotion are sliding, the number of high-speed actions increases considerably.

Some authors also performed a factorial analysis of several fitness test results and found that speed and agility had little in common statistically, which led them to conclude that they were relatively independent [31].

\section{Conclusions}

In this study, it was possible to describe inverse correlations between vertical jumps and linear velocity. The same type of correlation seems to exist in the CMJ and T-shape tests, showing that athletes who jump higher seem to have better patterns of agility. Despite the low specificity of the vertical jump tests among roller hockey players, these results suggest that jumps are an easy and good prediction sports training tool of linear speed and agility in skating among talented young roller hockey players.

\section{Disclosure statement}

No author has any financial interest or received any financial benefit from this research.

\section{Conflict of interest}

The authors state no conflict of interest.

\section{References}

1. Gonçalves CEB, Rama LML, Figueiredo AB. Talent identification and specialization in sport: an overview of some unanswered questions. Int J Sports Physiol Perform. 2012;7(4):390-393; doi: 10.1123/ijspp.7.4.390.

2. Murtagh CF, Brownlee TE, O’Boyle A, Morgans R, Drust B, Erskine RM. Importance of speed and power in elite youth soccer depends on maturation status. J Strength Cond Res. 2018;32(2):297-303; doi: 10.1519/ JSC.0000000000002367.

3. Reilly T, Williams AM, Nevill A, Franks A. A multidisciplinary approach to talent identification in soccer. J SportsSci.2000;18(9):695-702; doi:10.1080/0264041 0050120078.

4. Buekers M, Borry P, Rowe P. Talent in sports. Some reflections about the search for future champions. Mov Sport Sci - Sci Mot. 2015;88(2):3-12; doi: 10.1051/ sm/2014002. Available from: http:/www.mov-sportsciences.org/10.1051/sm/2014002.

5. Rodríguez FA. Functional evaluation of the roller hockey player [in Spanish]. Apunt Educ Física i Esports. 1991; 1991(23):51-62.

6. Stastny P, Tufano JJ, Kregl J, Petr M, Blazek D, Steffl M, et al. The role of visual feedback on power output during intermittent Wingate testing in ice hockey players. Sports. 2018;6(2):32; doi: 10.3390/sports6020032.

7. Clark MA, Lucett SC, Sutton BG. NASM essentials of personal fitness training. Baltimore: Wolters Kluwer Health; 2012.

8. Vaz VPS. Sports specialization in young male hockey players. A study of young athletes, the selection process, and the income structure [in Portuguese]. Coimbra: Universidade de Coimbra; 2011. Available from: https:// estudogeral.sib.uc.pt/handle/10316/17926?locale=pt.

9. Rebelo AN, Oliveira J. Association between speed, agility and muscular power of professional soccer players [in Portuguese]. Rev Port Cien Desp. 2006;6(3):342-348.

10. Coelho DB, Coelho LGM, Braga ML, Paolucci A, Cabido CET, Ferreira JB Jr., et al. Correlation between performance of soccer players in the 30-meter sprint test and in the vertical jump test [in Portuguese]. Motriz Rev Educ Fis. 2011;17(1):63-70; doi: 10.5016/1980 $-6574.2011 v 17 n 1 p 63$.

11. Mil-Homens P. Forms of force manifestation [in Portuguese]. In: Mil-Homens P, Pezarat Correia P, Vilhena de Mendoça G (eds.), Training of the force: biological principles and methods of training [in Portuguese]. Lisboa: Univeridade de Lisboa; 2015; 113-126.

12. Minamoto VB. Classification and adaptations of muscle fibers: a review [in Portuguese]. Fisioter Pesq. 2005; 12(3):50-55.

13. Hojka V, Stastny P, Rehak T, Gołas A, Mostowik A, Zawart M, et al. A systematic review of the main factors that determine agility in sport using structural equation modeling. J Hum Kinet. 2016;52:115-123; doi: 10.1515/hukin-2015-0199. 
A. Ferreira et al., Power condition, agility, and speed in young athletes

14. Sheppard JM, Young WB. Agility literature review: classifications, training and testing. J Sports Sci. 2006; 24(9):919-932; doi: 10.1080/02640410500457109.

15. Young WB, James R, Montgomery I. Is muscle power related to running speed with changes of direction? J Sports Med Phys Fitness. 2002;42(3):282-288.

16. De Carvalho Guincho AD. Relation between three agility tests: T test, 505 test, and ZIG-ZAG test: influence of maturational status, chronological age, and training age on the performance in the three tests [in Portuguese]. Porto: Universidade do Porto; 2007.

17. International Society for the Advancement of Kinanthopometry. International standards for anthropometric assessment. Underdale: International Society for the Advancement of Kinanthropometry; 2011.

18. Markovic G, Dizdar D, Jukic I, Cardinale M. Reliability and factorial validity of squat and countermovement jump tests. J Strength Cond Res. 2004;18(3):551555; doi: 10.1519/1533-4287(2004)18<551:RAFVOS $>2.0 . \mathrm{CO} ; 2$.

19. FIRS. Fédération Internationale Roller Sports. Technical Regulation. Lausanne: FIRS//Rink Hockey Technical Committee; 2017. Available from: http://old.rollersports.org/discipline/rink-hockey/regulations.

20. Pauole K, Madole K, Garhammer J, Lacourse M, Rozenek R. Reliability and validity of the T-test as a measure of agility, leg power, and leg speed in college-aged men and women. J Strength Cond Res. 2000;14(4): 443-450; doi: 10.1519/00124278-200011000-00012.

21. Pinheiro MMD. Physiological characterization of Portuguese hockey athletes in high performance skates [in Portuguese]. Lisboa: Universidade de Lisboa; 2013.

22. Coledam DHC, Arruda GA de, dos Santos JW, de Oliveira AR. Relationship of vertical, horizontal, and sextuple jumps with agility and speed in children [in Portuguese]. Rev Bras Educ Fís Esporte. 2013;27(1):43-53; doi: 10.1590/S1807-55092013000100005.

23. Burr JF, Jamnik VK, Dogra S, Gledhill N. Evaluation of jump protocols to assess leg power and predict hockey playing potential. J Strength Cond Res. 2007;21(4): 1139-1145; doi: 10.1519/R-21496.1.

24. West DJ, Owen NJ, Jones MR, Bracken RM, Cook CJ, Cunningham DJ, et al. Relationships between forcetime characteristics of the isometric midthigh pull and dynamic performance in professional rugby league players. J Strength Cond Res. 2011;25(11):3070-3075; doi: 10.1519/JSC.0b013e318212dcd5.

25. Dragula L, Lehnert M, Psotta R, Gonosová Z, Valenta S, Štastný P. The relative force in squat jump is the best laboratory predictor of sprint performance in adolescent soccer players. Hum Mov. 2017;18(5):83-90; doi: 10.5114/hm.2017.73622.

26. Wisløff U, Castagna C, Helgerud J, Jones R, Hoff J. Strong correlation of maximal squat strength with sprint performance and vertical jump height in elite soccer players. Br J Sports Med. 2004;38(3):285-288; doi: 10.1136/bjsm.2002.002071.
27. Carnaval P. Measures and evaluation in sports sciences [in Portuguese]. $6^{\text {th }}$ ed. Rio de Janeiro: Sprint; 2004.

28. Brughelli M, Cronin J, Levin G, Chaouachi A. Understanding change of direction ability in sport: a review of resistance training studies. Sports Med. 2008;38(12): 1045-1063; doi: 10.2165/00007256-200838120-00007.

29. Haukali E, Tjelta LI. Correlation between "off-ice" variables and skating performance among young male ice hockey players. Int J Appl Sports Sci. 2015;27(1):26-32; doi: 10.24985/ijass.2015.27.1.26.

30. Little T, Williams AG. Specificity of acceleration, maximum speed, and agility in professional soccer players. J Strength Cond Res. 2005;19(1):76-78; doi: 10.1519/ 14253.1.

31. Young WB, McDowell MH, Scarlett BS. Specificity of sprint and agility training methods. J Strength Cond Res. 2001;15(3):315-319; doi: 10.1519/1533-4287 (2001)015<0315:SOSAAT>2.0.CO;2. 